\title{
Interobserver variability of ventilatory anaerobic threshold in asymptomatic volunteers
}

\author{
Sabine Kaczmarek, Dirk Habedank ${ }^{2^{*}}$ D, Anne Obst ${ }^{3}$, Marcus Dörr ${ }^{1,3}$, Henry Völzke ${ }^{4}$, Sven Gläser ${ }^{3,5}$ and Ralf Ewert ${ }^{3}$
}

\begin{abstract}
Background: The ventilatory anaerobic threshold $\left(\mathrm{VO}_{2} @ A T\right)$ has been used in preoperative risk assessment and rehabilitation for many years. Our aim was to determine the interobserver variability of AT using cardiopulmonary exercise (CPET) data from a large epidemiological study (SHIP, Study of Health in Pomerania).

Methods: $\mathrm{VO}_{2} @ A T$ was determined from CPET of 1,079 cross-sectional volunteers, according to American Heart Association guidelines. VO $\mathrm{O}_{2} @ \mathrm{AT}$ determinations were compared between two experienced physicians, between physicians and qualified medical assistants, and between physicians or medical assistants and software-based algorithms. For the first 522 data sets, the two physicians discussed discrepant readings to reach consensus; the remaining data sets were analyzed without consensus discussion.
\end{abstract}

Results: VO $\mathrm{O}_{2} @ A T$ was detectable in 1,056 data sets. The physicians recorded identical VO $2 @ A T$ values in 319 out of 522 cases before consensus discussion (61.1\%; intraclass correlation coefficient [ICC]: 0.90; 95\% confidence interval [CI]: 0.88-0.92) and in 700 out of 1,056 cases overall (66.3\%; ICC: 0.95; 95\% Cl: 0.95-0.96), with an interobserver difference of $0 \pm 8 \%$ ( $95 \%$ limits of agreement [LOA]: $\pm 161 \mathrm{~mL} / \mathrm{min}$ ). The interobserver difference was $-2 \pm 18 \%$ (95\% LOA: $\pm 418 \mathrm{~mL} / \mathrm{min}$ ) between a physician and medical assistants, and $-19 \pm 24 \%$ to $-22 \pm 26 \%$ (95\% LOAs: $\pm 719-806 \mathrm{~mL} / \mathrm{min}$ ) between physicians or medical assistants and software-based algorithms.

Conclusions: Experienced physicians show high agreement when determining AT in asymptomatic volunteers. However, agreement between physicians and qualified medical assistants is lower, and there is substantial deviation in AT determination between physicians or medical assistants and software-based algorithms. This must be considered when using AT as a decision tool.

Keywords: Cardiopulmonary exercise testing, Anaerobic threshold, Observational study, Reproducibility

\section{Background}

Cardiopulmonary exercise testing (CPET) is a key method in clinical diagnostics, in assessment of illness severity, in determination and monitoring of therapy, and in prognostic stratification. The performance of CPET and interpretation of the results are generally well standardized internationally $[1,2]$. Among other CPET parameters, the ventilatory anaerobic threshold (AT) has been used in pre-operative risk assessment for many years [3], and recently the predictive value of AT determination has expanded from valvular

\footnotetext{
* Correspondence: d.habedank@drk-kliniken-berlin.de

${ }^{2}$ DRK Kliniken Berlin Köpenick, Klinik für Kardiologie, S.-Allende-Str. 2-8, 12555

Berlin, Germany

Full list of author information is available at the end of the article
}

and thoracic surgery to pancreatic and liver resection [4]. An increase of AT is a decisive response to exercise prescription in patients with chronic heart failure [5, 6], pulmonary disease [6] or stroke [7]. The importance of AT and its exact determination is acknowledged in recent guideline updates $[8,9]$.

AT is defined as the exercise level at which ventilation (VE) begins to increase exponentially relative to the increase in oxygen uptake $\left(\mathrm{VO}_{2}\right)$ [10]. There are wide differences in AT detection procedures and terminology $[11,12]$. From a strict physiological viewpoint, there are two ventilatory thresholds, the first reflecting the transition from aerobic to anaerobic metabolism, and the second one from anaerobic metabolism to metabolic acidosis. Throughout 
this paper, we use the term 'AT' to refer to the first threshold. Methodological basics and practical guidelines for AT determination have been thoroughly reviewed elsewhere $[9,13]$.

The American Heart Association (AHA) Scientific Statement on CPET in adults [10] notes that confidence in determining AT may be increased by having two or three independent, experienced observers perform the calculation. If AT is calculated by software-based algorithms, it should be checked by an individual experienced in CPET and its assessment [10]. The repeatability of CPET parameters in healthy individuals [14] and intraindividual determination of the AT (test-retest comparison) in chronic disease cohorts $[15,16]$ is generally high. However, studies of interobserver variability of AT are limited. They refer to different populations, including healthy volunteers [17] and patients with heart failure [16, 18-20], congenital heart failure [21], pulmonary arterial hypertension [22], chronic obstructive pulmonary disease (COPD) [23] and mixed etiologies $[24,25]$. Furthermore, the published studies vary substantially in terms of sample size (from $n=6$ to $n=428$ ) and statistical interpretation. Studies comparing softwarebased AT determination with visual determination of AT by clinically experienced readers have produced heterogeneous results [23, 25].

Therefore, the aim of our study was to determine the interobserver variability of AT using CPET data from a large population-based epidemiological study (Study of Health in Pomerania [SHIP]).

\section{Methods}

\section{Study design and participants}

SHIP is a large epidemiological study of 4,308 volunteers (age 20-79 years) drawn from the citizens registry of northeast Germany (West Pomerania). The volunteers were first evaluated from 1997 to 2001 (SHIP-0). The third follow up study (SHIP-3) re-evaluated 1,738 volunteers from the initial sample between 2014 and 2016. The methodological details of the overall study [26] and its pneumological aspects [27] have been published previously.

SHIP-3 was completed by 1,718 volunteers; 1,128 (65.6\%) of the volunteers underwent CPET, and 1,079 had full data available and were included in the analyses presented here. All anamnestic data based on survey of the volunteers by professional interviewer and covered smoking status (current, former, never smoker), physical activity, previous myocardial infarction, atrial fibrillation, heart failure, heart operation, pacemaker, chronic bronchitis, and asthma. These demographic data are presented in Table 1.

\section{CPET}

All volunteers underwent symptom-limited exercise testing until maximum exhaustion on an electromagnetically braked bicycle ergometer in an upright sitting position
(Ergoselect 100, Ergoline, Germany), using the modified Jones protocol: $3 \mathrm{~min}$ measurements at rest, $1 \mathrm{~min}$ unloaded cycling, stepwise increase of workload by $16 \mathrm{~W} /$ $\mathrm{min}$, and $5 \mathrm{~min}$ recovery. Gas exchange and ventilation were measured breath by breath using an $\mathrm{Oxycon} \mathrm{Pro}^{\circ}$ system (VIASYS Healthcare GmbH, Hoechberg, Germany) with a CPET (7450 V2) mask. Calibration was performed before every exercise test [28].

\section{Calculation of AT}

Values of AT are given as $\mathrm{VO}_{2}$ at the aerobic-anaerobic threshold $\left(\mathrm{VO}_{2} @ \mathrm{AT}\right)$ in $\mathrm{mL} / \mathrm{min}$. AT was determined manually according to current guidelines [9, 10, 13]. First, the slope of the $\mathrm{VCO}_{2}$ versus $\mathrm{VO}_{2}$ relationship was analyzed, and AT identified as the point of transition in the $\mathrm{VCO}_{2}$ versus $\mathrm{VO}_{2}$ slope from $<1$ to $>1$ ("V-slope method"). Second, in cases where the V-slope method could not be applied, AT was defined as the lowest point of the ventilatory equivalent for oxygen $\left(\mathrm{VE} / \mathrm{VO}_{2}\right)$. The software-based AT determination used the VIASYS software calculation tool (JLab Labmanager V5.32.0). Manual assessment included data from the fourth minute of exercise until a respiratory exchange ratio (RER) of 1 was exceeded. Raw data were averaged at intervals of $10 \mathrm{~s}$ for both methods (manual and software-based), and the AT was determined using 30-s rolling averages calculated every $10 \mathrm{~s}$.

\section{Interobserver comparisons}

Two physicians and two medical technical assistants determined values of AT manually. The physicians had 2 years and 20 years of experience in CPET, and both underwent a training phase in which they evaluated the same 400 CPET data sets (using 10- and 30-s intervals) to ensure adherence to the AHA guidelines [10] for determination of AT (data not shown). The medical technical assistants completed a special education program and were certified in the performance, supervision, and interpretation of CPET.

Software-based AT values and values determined by medical assistants were used directly in the interobserver agreement analysis. The determination of AT values by the physicians was conducted in two phases (Fig. 1). In phase 1 (the first $522 \mathrm{CPETs}$ ), each physician independently determined the AT for each CPET, and cases with a difference of $>10 \%$ underwent consensus discussion between the two physicians to reach agreement (if agreement was not reached, the differing values as originally calculated were taken into the statistical analysis). In phase 2, the remaining 534 CPETs were analyzed independently by each physician without consensus discussion.

Levels of interobserver agreement were calculated between the two physicians in phase 1 (before and after the consensus discussion) and in phases 1 and 2 combined (after the phase 1 consensus discussion). AT values determined by the medical assistants were 
Table 1 Descriptive Statistics of the Study Population $(N=1,056)$

\begin{tabular}{|c|c|c|c|}
\hline Parameter & Missing data, $\mathrm{n}$ & $n(\%)$ & Median (interquartile range) \\
\hline Men & & $515(48.8 \%)$ & \\
\hline Age, years & & & $60(49-69)$ \\
\hline Weight, kg & & & $79(69-90)$ \\
\hline Height, cm & & & $169(162-176)$ \\
\hline $\mathrm{BMI}, \mathrm{kg} / \mathrm{m}^{2}$ & & & $27.3(24.6-30.6)$ \\
\hline $\mathrm{BMI} \geq 30 \mathrm{~kg} / \mathrm{m}^{2}$ & & $298(28.2 \%)$ & \\
\hline Smoking status & 2 & & \\
\hline Never smokers & & $404(38.3 \%)$ & \\
\hline Former smokers & & $485(46.0 \%)$ & \\
\hline Current smokers & & $165(15.7 \%)$ & \\
\hline Physically active ${ }^{a}$ & & $870(82.4 \%)$ & \\
\hline Myocardial infarction & 2 & $25(2.4 \%)$ & \\
\hline Atrial fibrillation & 8 & $54(5.1 \%)$ & \\
\hline Heart failure & 125 & $30(3.2 \%)$ & \\
\hline Fractional shortening below normal ${ }^{b}$ & 324 & $2(0.3 \%)$ & \\
\hline Heart operation & 1 & $22(2.1 \%)$ & \\
\hline Pacemaker & 3 & $5(0.5 \%)$ & \\
\hline Previous pulmonary disease & 2 & $52(4.9 \%)$ & \\
\hline Chronic bronchitis $^{c}$ & 1 & $53(5.0 \%)$ & \\
\hline Asthma & 4 & $55(5.2 \%)$ & \\
\hline Maximum exercise duration, s & & & $536(420-670)$ \\
\hline Maximum power, W & & & $148(132-196)$ \\
\hline peak $\mathrm{VO}_{2}, \mathrm{~mL} / \mathrm{min}$ & 2 & & $1,812(1,482-2,292)$ \\
\hline $\mathrm{VO}_{2} @ \mathrm{AT}, \mathrm{mL} / \mathrm{min}$ & & & $1,009(867-1,204)$ \\
\hline$V_{O_{2}} @ A T /$ peak $V_{2}$ reference, $\%^{d}$ & & & $54.6(47.1-63.7)$ \\
\hline $\mathrm{VO}_{2} @ \mathrm{AT} /$ peak $\mathrm{VO}_{2}$ reference $<45 \%{ }^{\mathrm{d}}$ & & $163(15.4 \%)$ & \\
\hline RER@AT & & & $0.82(0.77-0.86)$ \\
\hline $\mathrm{FEV}_{1} / \mathrm{FVC}, \%$ & 3 & & $75.7(71.4-79.7)$ \\
\hline $\mathrm{FEV}_{1} / \mathrm{FVC}<70 \%$ & & $199(18.9 \%)$ & \\
\hline
\end{tabular}

Anamnestic data based on survey by professional interviewer. Continuous data are expressed as the median $\left(25^{\text {th }} ; 75^{\text {th }}\right.$ quartile). Nominal data are given as percentages

"Volunteers were asked about their physical activity and categorized as "Physically active" in case of $1-2 \mathrm{~h}$ of activity per week in summer and winter

b The echocardiographic parameter "fractional shortening" was calculated as (left ventricular diastolic - systolic diameter [in $\mathrm{cm}$ ]) $\times 100$. Pathologic values were $<$ $19 \%$ in males and $<21 \%$ in females

' Subgroups may overlap

${ }^{d}$ Predicted values were calculated according to Gläser $\mathrm{S}$ et al. [28] These were: peak $\mathrm{VO}_{2}$ in males $=254.76-22.69 \times$ age [years] $+17.25 \times$ height [cm] $+4.41 \times$ weight $[\mathrm{kg}]$; and peak $\mathrm{VO}_{2}$ in females $=-54.74-9.81 \times$ age [years] $+9.92 \times$ height $[\mathrm{cm}]+8.06 \times$ weight $[\mathrm{kg}]$

$B M I$ Body mass index, peak $V_{2}$ Peak oxygen uptake, $\mathrm{VO}_{2} @ A T$ Oxygen uptake at the aerobic-anaerobic threshold, RER Respiratory exchange ratio, FEV $/$ /FVC Forced expiratory volume in $1 \mathrm{~s} /$ forced vital capacity

compared with the values determined by each of the physicians (after the consensus discussion). Finally, AT values determined by the medical assistants and each of the physicians (after the consensus discussion) were compared with those determined by the software.

\section{Statistical analysis}

Continuous data are expressed as median (interquartile range), and nominal data are given as percentages.
To assess interobserver agreement, the intraclass correlation coefficient (ICC) was calculated. BlandAltman plots were used to compare the $\mathrm{VO}_{2} @ \mathrm{AT}$ calculations of the different readers and the software. In addition, a Passing-Bablok regression analysis was performed comparing software- and manually-derived $\mathrm{VO}_{2} @ \mathrm{AT}$.

The reliability of $\mathrm{VO}_{2} @ \mathrm{AT}$ readings was assessed using the typical error (TE), the coefficient of variation of the $\mathrm{TE}\left(\mathrm{CV}_{\mathrm{TE}}\right)$, and limits of agreement, expressed as absolute 

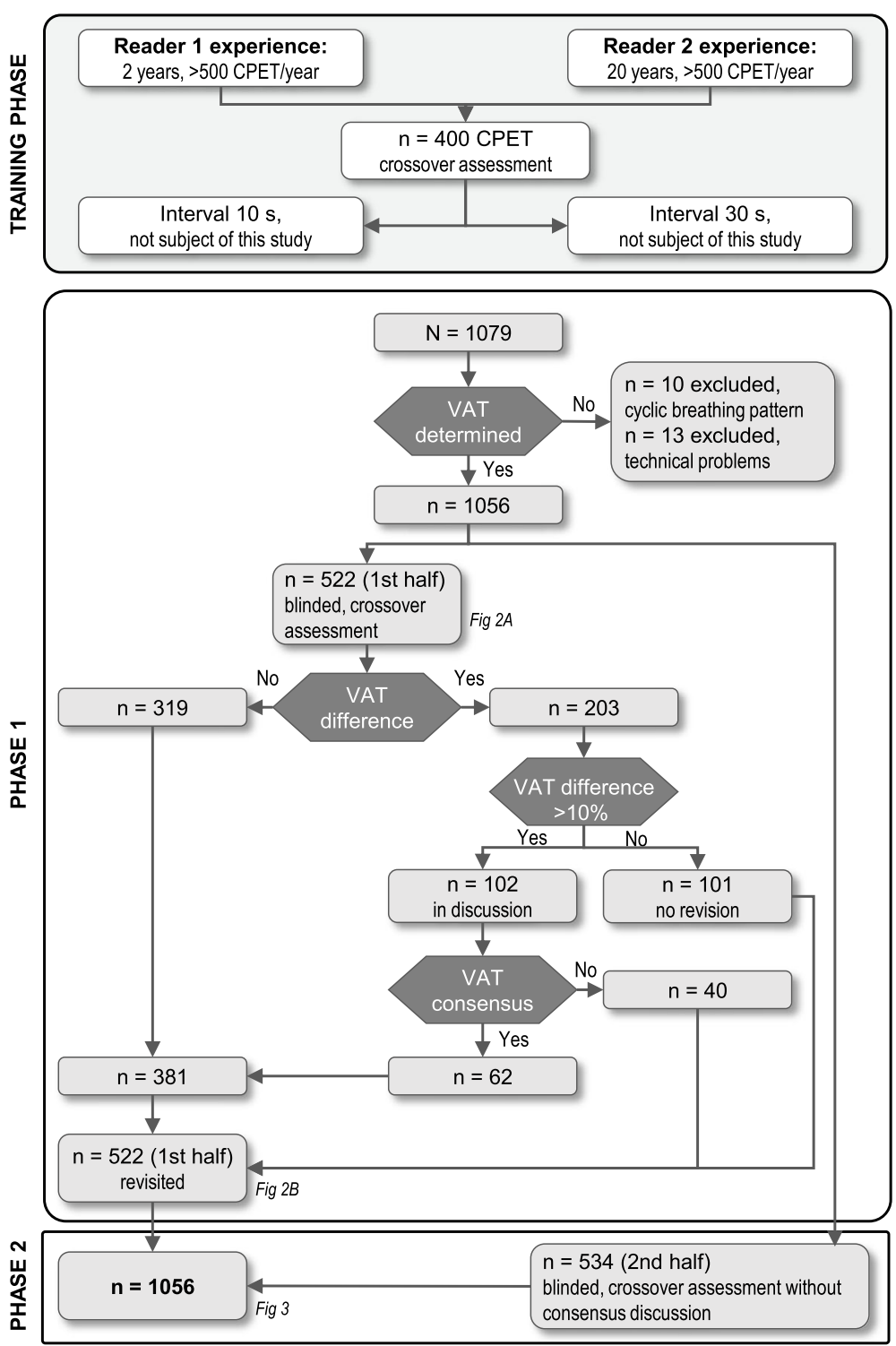

Fig. 1 Flow chart summarizing the study of interobserver agreement in AT assessment between two physicians. CPET= cardiopulmonary exercise training; $A T$ = ventilatory anaerobic threshold

values (LOA) and as a percentage of the mean $\mathrm{VO}_{2} @ \mathrm{AT}$ (LOA\%).

Statistical analyses were performed using SAS version 9.4 (SAS Institute, Inc., NC, USA).

\section{Results}

Out of the 1,079 available data sets, 10 (0.9\%; all showing an unstable cyclic breathing pattern) had non-detectable AT according to at least one physician reader and were therefore excluded from the analysis $(7[0.6 \%]$ were deemed uninterpretable by both physicians). Thirteen data sets with technical problems were also excluded. Thus, the final interobserver agreement analysis contained 1,056 data sets. The study participants represented a typical and asymptomatic but not strictly healthy population with a median body mass index of $27.3 \mathrm{~kg} / \mathrm{m}^{2} ; 82.4 \%$ selfreported being physically active, $15.7 \%$ were active smokers and 5.0\% had chronic bronchitis. In total, 18.9\% had pulmonary obstruction (forced expiratory volume in $1 \mathrm{~s}$ /forced vital capacity $<70 \%)$. The median RER at AT was $0.82(0.77-0.86)$, consistent with the reported training status and sure beyond exercise to exhaustion.

\section{Interobserver agreement between physicians}

Phase 1 showed complete agreement (i.e. $\mathrm{VO}_{2} @ \mathrm{AT}$ difference $=0$ ) between the two physicians in 319 of 522 cases (61.1\%). The mean difference was $-0.1 \mathrm{~mL} / \mathrm{min}$ and the LOA $\pm 250 \mathrm{~mL}$ (Fig. 2 and Table 2). 103 cases showed a 


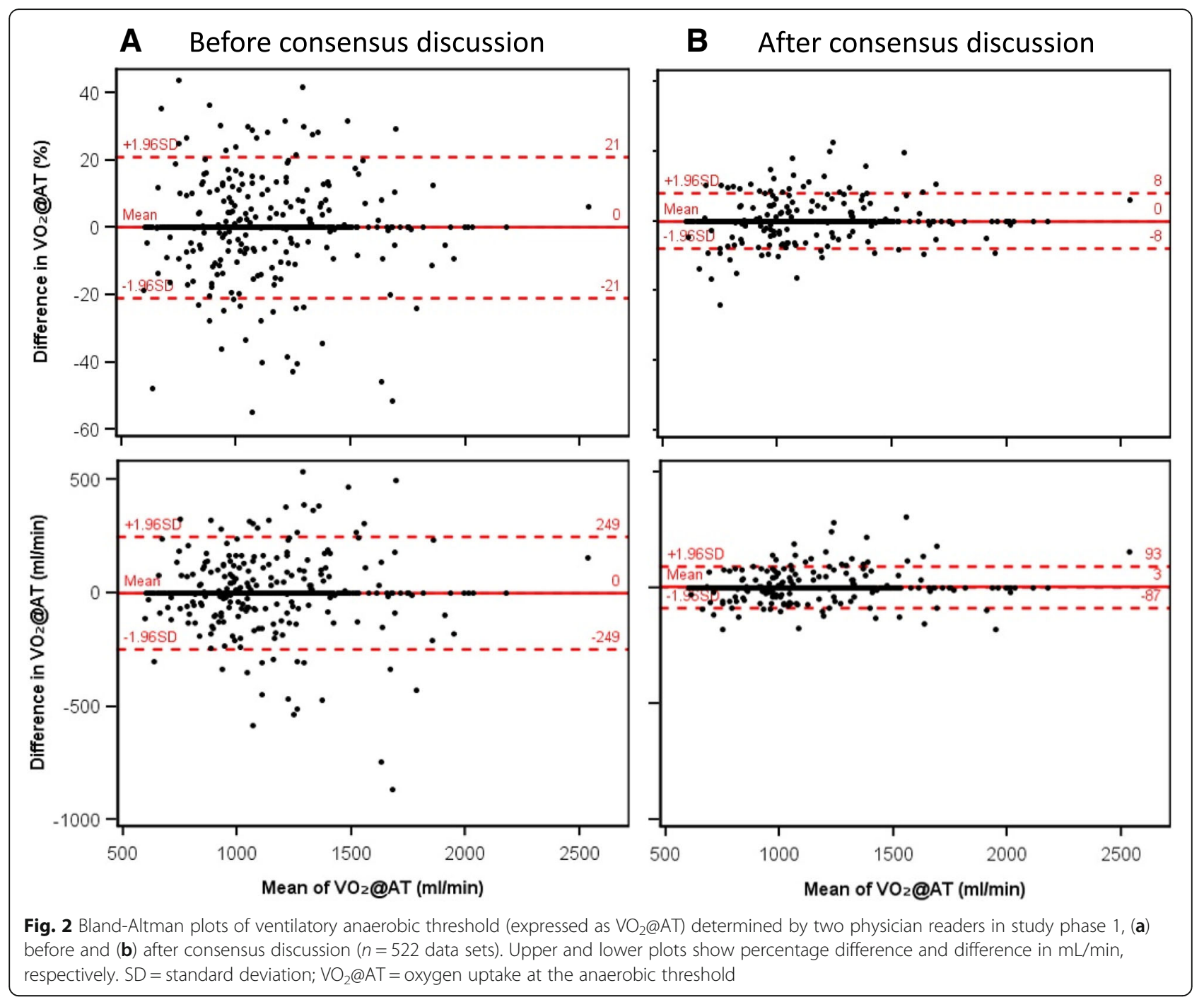

difference of $>10 \%$ in $\mathrm{VO}_{2} @ \mathrm{AT}$; following consensus discussion of these cases, the agreement increased to 382 of 522 cases (73.2\%, Fig. 2 and Table 2). In phases 1 and 2 combined (after phase 1 consensus discussion), the physicians agreed in 700 out of 1,056 cases (66.3\%), with an ICC of 0.95 (0.95-0.96) (Fig. 3 and Table 2). The mean difference was $+5 \mathrm{~mL} / \mathrm{min}$ and the LOA $\pm 161 \mathrm{~mL} / \mathrm{min}$, with an interobserver variability between physicians of $\pm 8 \%$.

\section{Agreement between physicians and assistants}

The interobserver agreement analysis between physician readers 1 and 2 and trained assistants included 794 and 793 data sets, respectively. There were no systematic differences in calculated $\mathrm{VO}_{2} @ \mathrm{AT}$ between these groups (Fig. 4 and Table 2), although agreement was somewhat lower than that observed between the two physicians. The interobserver variability between physicians and medical assistants was $\pm 18 \%$ (LOAs: \pm 408 and 418 $\mathrm{mL} / \mathrm{min}$ ).
Manual versus software-based methods

The comparison between software-based and manuallyderived $\mathrm{VO}_{2} @ \mathrm{AT}$ contained 655 (physician 1), 658 (physician 2), and 654 (medical assistants) data sets (Fig. 5 and Table 2). The software-based $\mathrm{VO}_{2} @ A T$ tended to be higher than the manually-derived $\mathrm{VO}_{2} @ \mathrm{AT}$ at higher $\mathrm{VO}_{2} @ \mathrm{AT}$ values (overall mean differences, $275-321 \mathrm{~mL} / \mathrm{min}$ ). The interobserver variability between the software and the physicians/assistants was $\pm 24-26 \%$ (95\% LOAs: $\pm 719-806 \mathrm{~mL} / \mathrm{min}$ ).

\section{Discussion}

Our epidemiological study contained over 1,000 participants, and experienced readers were able to determine an AT in $>99 \%$ of cases. This proportion is consistent with the literature: despite adequate exhaustion and experienced readers, AT determination is not always possible [10], especially in individuals with periodic breathing patterns (as seen in our study) and in patients with chronic heart failure 
Table 2 Interobserver Agreement for Determination of Ventilatory Anaerobic Threshold $\left(\mathrm{VO}_{2} @ \mathrm{AT}\right)$

\begin{tabular}{|c|c|c|c|c|c|c|c|c|c|}
\hline & $n$ & $\begin{array}{l}\text { Mean VO } \mathrm{V}_{2} @ \mathrm{AT} \\
( \pm \mathrm{SD}), \mathrm{mL} / \mathrm{min}\end{array}$ & $\begin{array}{l}\text { Mean difference } \\
\left( \pm S D_{d}\right), \mathrm{mL} / \mathrm{min}\end{array}$ & $\begin{array}{l}\text { 95\% LOA, } \\
\mathrm{mL} / \mathrm{min}\end{array}$ & $T E^{b}$ & $\begin{array}{l}\text { Mean difference } \\
\left( \pm S D_{d}\right), \%\end{array}$ & $\begin{array}{l}95 \% \mathrm{LOA}_{,}^{\mathrm{a}} \\
\%\end{array}$ & ICC (95\% Cl) & $\begin{array}{l}\mathrm{CV}_{\mathrm{TE},}{ }^{\mathrm{C}} \\
\%\end{array}$ \\
\hline \multicolumn{10}{|l|}{ Before consensus discussion } \\
\hline Reader 1 vs reader 2 (phase 1) & 522 & $1,093( \pm 279)$ & $0( \pm 127)$ & \pm 250 & 90 & $0( \pm 11)$ & \pm 21 & $\begin{array}{l}0.901(0.884- \\
0.916)\end{array}$ & 8.2 \\
\hline \multicolumn{10}{|l|}{ After consensus discussion } \\
\hline Reader 1 vs reader 2 (phase 1) & 522 & $1,085( \pm 283)$ & $3( \pm 46)$ & \pm 90 & 32 & $0( \pm 4)$ & \pm 8 & $\begin{array}{l}0.987(0.985- \\
0.989)\end{array}$ & 3.0 \\
\hline $\begin{array}{l}\text { Reader } 1 \text { vs reader } 2 \text { (phase } 1 \\
+2 \text { ) }\end{array}$ & 1,056 & $1,048( \pm 246)$ & $5( \pm 82)$ & \pm 161 & 58 & $0( \pm 8)$ & \pm 15 & $\begin{array}{l}0.952(0.946- \\
0.957)\end{array}$ & 5.6 \\
\hline Reader 1 vs trained assistants & 794 & $1,073( \pm 292)$ & $-36( \pm 213)$ & \pm 418 & 151 & $-2( \pm 18)$ & \pm 34 & $\begin{array}{l}0.759(0.728- \\
0.787)\end{array}$ & 14.0 \\
\hline Reader 2 vs trained assistants & 793 & $1,070( \pm 289)$ & $-42( \pm 208)$ & \pm 408 & 147 & $-3( \pm 18)$ & \pm 34 & $\begin{array}{l}0.762(0.731- \\
0.790)\end{array}$ & 13.8 \\
\hline Reader 1 vs computer analysis & 655 & $1,215( \pm 371)$ & $-313( \pm 409)$ & \pm 801 & 289 & $-22( \pm 26)$ & \pm 51 & $\begin{array}{l}0.350(0.281- \\
0.415)\end{array}$ & 23.8 \\
\hline Reader 2 vs computer analysis & 658 & $1,210( \pm 367)$ & $-321( \pm 411)$ & \pm 806 & 291 & $-22( \pm 26)$ & \pm 51 & $\begin{array}{l}0.330(0.260- \\
0.396)\end{array}$ & 24.0 \\
\hline $\begin{array}{l}\text { Trained assistants vs computer } \\
\text { analysis }\end{array}$ & 654 & $1,236( \pm 407)$ & $-275( \pm 367)$ & \pm 719 & 259 & $-19( \pm 24)$ & \pm 48 & $\begin{array}{l}0.519(0.461- \\
0.573)\end{array}$ & 21.0 \\
\hline
\end{tabular}

a $95 \% \mathrm{LOA}= \pm 1.96 \times \mathrm{SD}_{\mathrm{d}}$

${ }^{\mathrm{b}} \mathrm{TE}=\mathrm{SD}_{\mathrm{d}} / \sqrt{2}$

${ }^{c} \mathrm{CV}$ TE $=\mathrm{TE} /$ mean VO $\mathrm{O}_{2} @ \mathrm{AT} \times 100$

C Confidence interval, $C V_{T E}$ Coefficient of variation of the TE, $d$ Differences, ICC Intraclass correlation coefficient, LOA Limits of agreement, SD Standard deviation, TE Typical error, $V O_{2} @ A T$ Oxygen uptake at the aerobic-anaerobic threshold $[\mathrm{mL} / \mathrm{min}]$

(AT was indeterminate in $16 \%$ of 1,679 tests in the Fix-Heart Failure-5 trial [16], 17\% of 398 tests in the Heart Failure-ACTION trial [15], and $29 \%$ of 331 tests in a multicenter trial by Cohen-Solal et al. [19]). In contrast to these studies, we intended to determine AT in a typical population, and the demographic characteristics of our study population matched this criterion.

Our data show that after a training period with 400 exercise tests, the subsequent analysis of $>1,000$ data sets by two physicians resulted in an ICC of 0.95 (95\% confidence interval [CI]: 0.95-0.96), and $\mathrm{VO}_{2} @ \mathrm{AT}$ values within the $95 \%$ LOA had a difference of $\pm 161 \mathrm{~mL} / \mathrm{min}$ $\left(\mathrm{SD}_{\mathrm{d}} \pm 8 \%\right)$. In phase 1 (the first 522 data sets), the consensus discussion increased the ICC to 0.99 and lowered the difference within the $95 \% \mathrm{LOA}$ to $\pm 90 \mathrm{~mL} / \mathrm{min}\left(\mathrm{SD}_{\mathrm{d}}\right.$ $\pm 4 \%$ ). A comparably high ICC of 0.98 (95\% CI: $0.97-$ $0.99)$ was shown in a study of 23 healthy volunteers undergoing cycle ergometer testing [23]. By contrast, analysis of 92 patients with COPD in the same study resulted in an ICC of 0.72 (95\% CI: 0.60-0.81) [23].
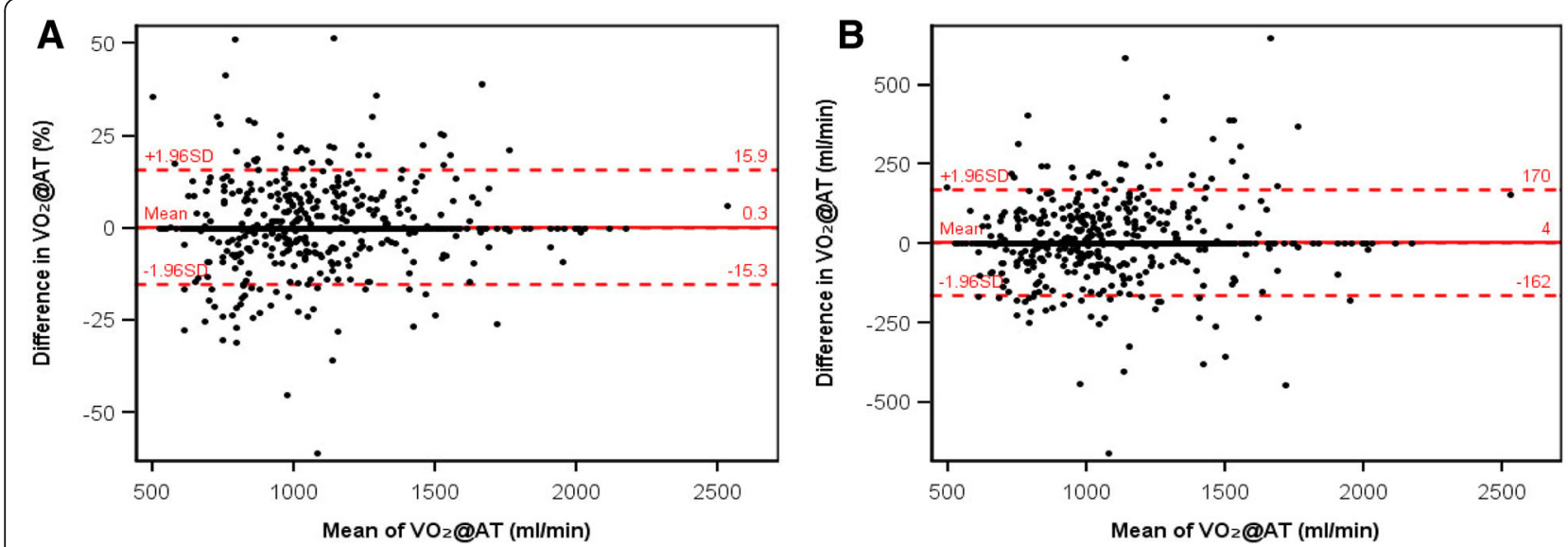

Fig. 3 Bland-Altman plots of ventilatory anaerobic threshold (expressed as $\mathrm{VO}_{2} @ A T$ ) determined by two physician readers in study phase 1 (after consensus discussion) and phase 2 combined ( $n=1,056$ data sets). a Percentage difference. $\mathbf{b}$ Difference in $\mathrm{mL} / \mathrm{min}$. $\mathrm{SD}=$ standard deviation; $\mathrm{VO}_{2} @ \mathrm{AT}=$ oxygen uptake at the anaerobic threshold 


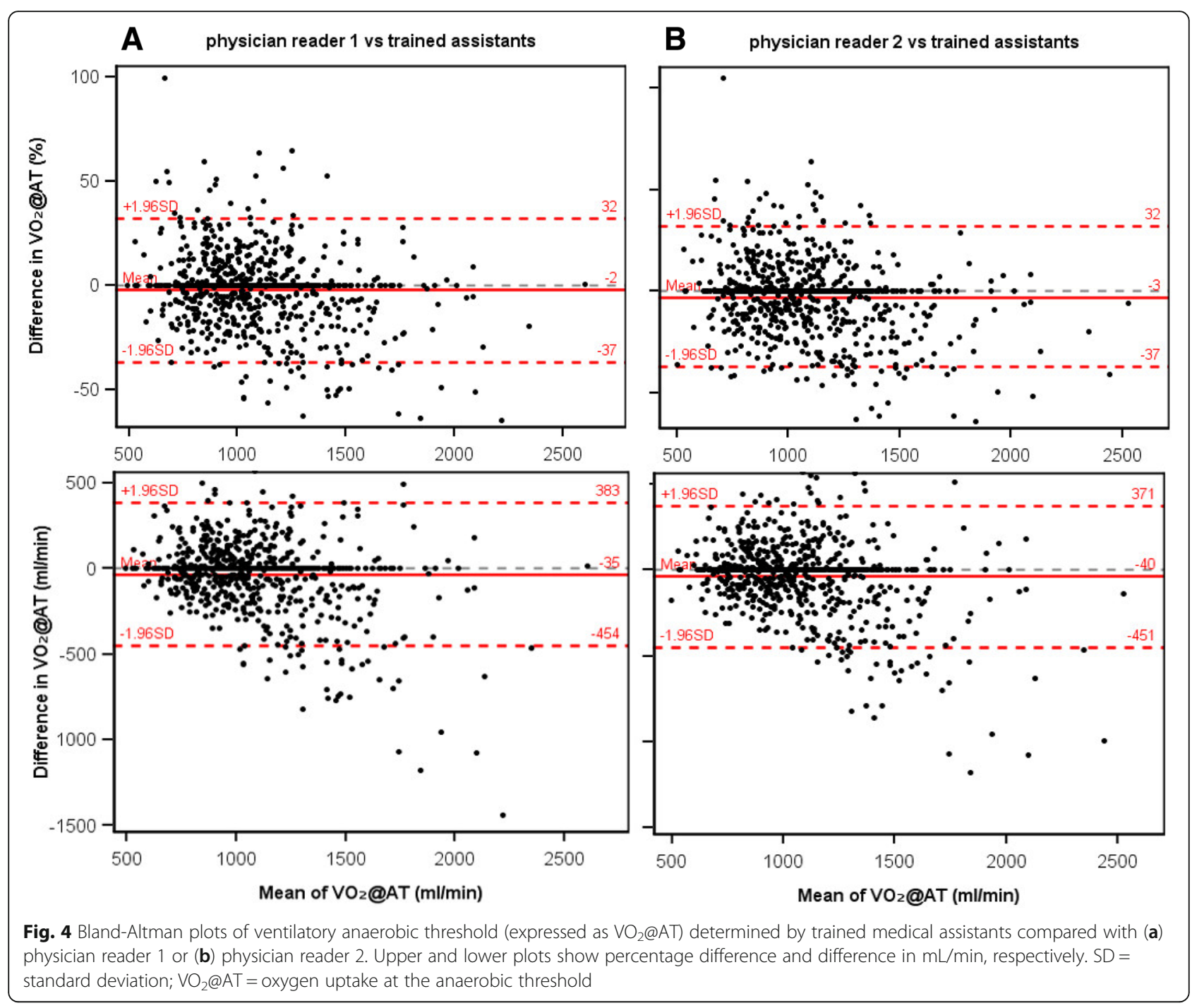

Studies of AT in patient populations undergoing exercise testing with a treadmill ergometer revealed a range of ICCs, from 0.64 in 16 patients with chronic heart failure [20] to 0.85 in 445 tests of patients before vascular operation [25] and 0.88-0.97 (with three readers) in 13 children with congenital heart failure [21].

The software-based algorithm used in our study showed substantial differences in all statistical parameters when compared with manual assessment by physicians or medical assistants (Table 2). However, comparison with previously published studies is difficult, because the softwarebased AT determination was performed using different algorithms. Dubé et al. [23] used the LAB Manager version 5.3.0.4 (Cardinal Health, Höchberg, Germany) and Vainshelboim et al. [25] used the COSMED system (Rome, Italy) and special analytic software, whereas our study used VIASYS software (JLab Labmanager V5.32.0).

The absolute differences in the AT values calculated by the physician readers deserve special interest from the clinician's viewpoint. Our study assessed AT in asymtomatic volunteers and showed a difference of $5 \pm 82 \mathrm{~mL} / \mathrm{min}$ (mean $\pm \mathrm{SD}_{\mathrm{d}}$ ) between the two readers, which corresponds to a $95 \%$ LOA of $\pm 161 \mathrm{~mL} / \mathrm{min}$. The study of patients with COPD mentioned above [23] showed a mean interobserver difference of $189 \pm 115 \mathrm{~mL} / \mathrm{min}(95 \% \mathrm{LOA}:-35-413 \mathrm{~mL} /$ $\mathrm{min})$. In patients with chronic heart failure the mean interobserver difference was $13 \pm 105 \mathrm{~mL} / \mathrm{min}$ (95\% LOA: $194-220 \mathrm{~mL} / \mathrm{min}$ ) [16]. Other authors reported median interobserver differences, expressed in relation to body weight $(\mathrm{mL} / \mathrm{kg} / \mathrm{min})[18]$, in percent [24], or in absolute terms ( $\mathrm{mL} / \mathrm{min})$ [22]. The latter study analyzed 42 patients with pulmonary hypertension and showed differences according to the readers' experience, with median differences in AT ranging from $20 \mathrm{~mL} / \mathrm{min}$ (for very experienced readers) to $60 \mathrm{~mL} / \mathrm{min}$ (for less experienced readers). The median interobserver difference overall was $36 \mathrm{~mL} / \mathrm{min}$ (6.4\%) [22].

Although interobserver differences between physicians were low in our study, larger differences were seen when 


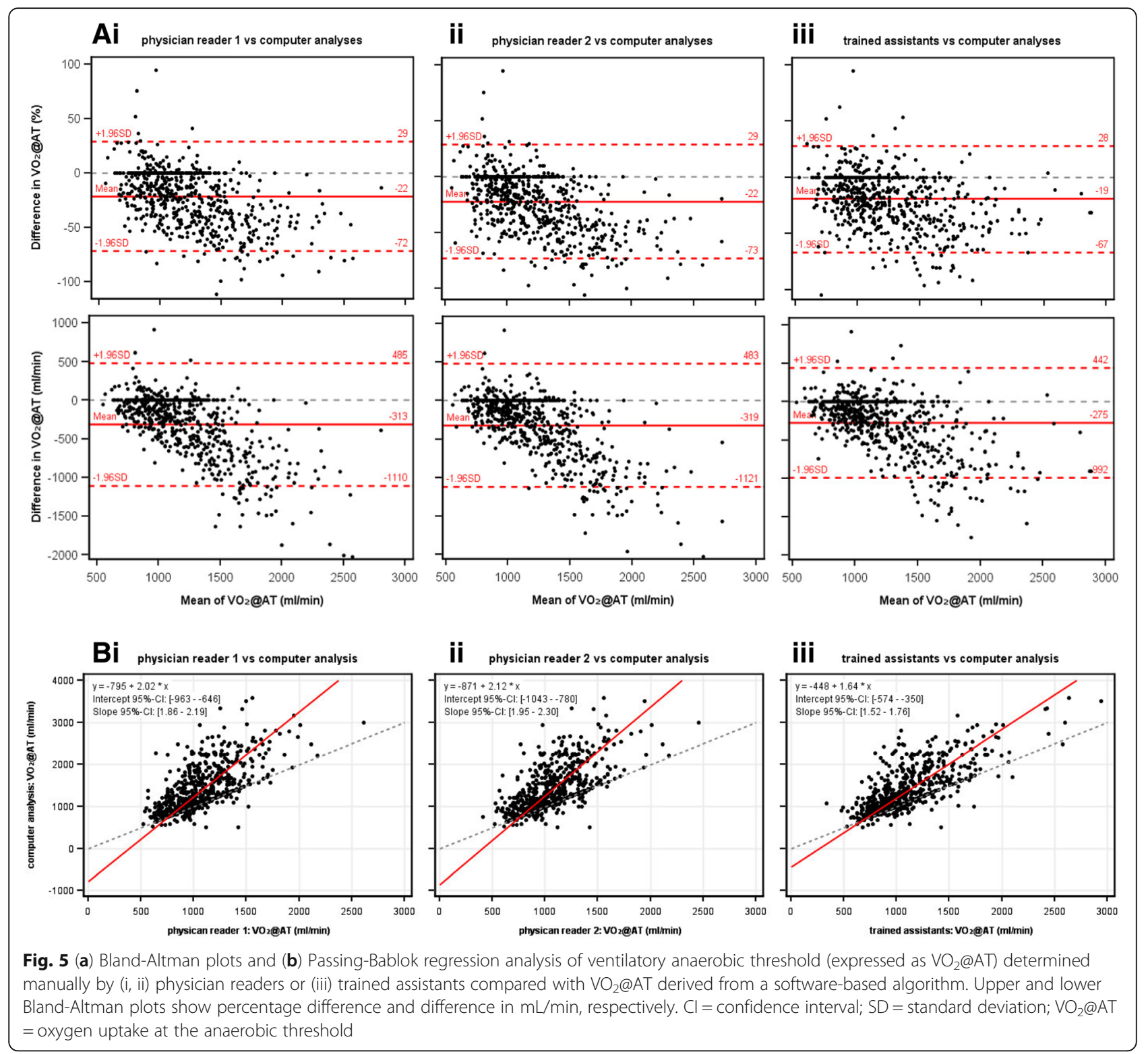

comparing medical assistants' readings with those taken by physicians (95\% LOA: approx. $400 \mathrm{~mL} / \mathrm{min}$ ) and particularly when comparing software-based versus manually-derived readings ( $95 \%$ LOA: $\pm 719-806 \mathrm{~mL} / \mathrm{min}$ ). This is partly contradictory to the recent recommendations of the AHA which include AT determination in the pre-surgical risk assessment algorithm for non-cardiac surgery [8]. Possible consequences of our calculated 95\% LOA can be shown on the basis of this recommendation: if the AT of a patient weighing $70 \mathrm{~kg}$ was determined by a physician to be 10.0 $\mathrm{mL} / \mathrm{kg} / \mathrm{min}$, which is lower than the accepted cut-off for mortality risk in abdominal surgical procedures $(11 \mathrm{~mL} / \mathrm{kg} /$ min) [29], it could also be determined as $13.4 \mathrm{~mL} / \mathrm{kg} / \mathrm{min}(+$ $34 \%$, upper LOA) by a medical assistant or even $15.1 \mathrm{~mL} / \mathrm{kg} /$ $\min (+51 \%)$ by a software-based algorithm. In this context, at least the software-based AT calculation could lead to a patient being classed (perhaps wrongly) as having an acceptable mortality risk. The determination of AT before exercise training in rehabilitation may be less critical; however, physicians should be aware of the LOA before prescribing aerobic exercise training. The benefit of these individual exercise doses has recently been shown in cardiac [30] and pulmonary diseases [6]. Exact determination of the AT and an awareness of the variability in AT calculation will enhance the application of AT in future pre-operative risk assessment, rehabilitation and study design.

\section{Limitations}

The averaging of raw data was performed in accordance with the AHA Scientific Statement on CPET [10]: "for 
routine clinical use, if feasible, the averaging of data over 20 - to 30-second intervals is generally sufficient to reduce the effect of random noise in breath-by-breath measurements". Other guidelines [13] recommend a rolling averaging of data over 8-10 breaths for AT determination. Both the interval and the number of breaths can be delayed up to 15 breaths, leading to a smoothing of curves.

We primarily used the V-slope method to detect the AT. Future studies should take the average of different methods of AT calculation, because this could yield more accurate values than a single AT calculation, especially in healthy resp. asymptomatic volunteers [31].

In accordance with other authors, we excluded the first minute of exercise from the analysis. This should avoid confounding of our results by a "pseudo threshold", which can be caused by hyperventilation at the start of exercise [23].

\section{Conclusions}

In summary, our analysis of CPET data from $>1,000$ asymptomatic volunteers shows varying degrees of interobserver variability and supports the need for independent assessment of essential CPET parameters by more than one reader. Furthermore, the data presented here may inform the calculation of statistical power in future clinical studies. Interobserver variability should be considered when determining AT values for pre-operative risk assessment and before prescription of aerobic exercise training.

\section{Abbreviations}

AHA: American Heart Association; AT: Anaerobic threshold; BMI: Body mass index; Cl: Confidence interval; COPD: Chronic obstructive pulmonary disease; CPET: Cardiopulmonary exercise testing; $\mathrm{CV}_{\mathrm{TE}}$ : Coefficient of variation of the typical error; $\mathrm{FEV}_{1}$ : Forced expiratory volume in $1 \mathrm{~s}$; FS: Fractional shortening; FVC: Forced vital capacity; ICC: Intraclass correlation coefficient; LOA: Limits of agreement; RER : Respiratory exchange ratio; SD: Standard deviation; $\mathrm{SD}_{d}$ : Standard deviation of mean difference; SHIP : Study of Health in Pomerania; TE: Typical error; VE: Ventilation; $\mathrm{VE} / \mathrm{NO}_{2}$ : Ventilatory equivalent for oxygen; $\mathrm{VO}_{2}$ : Oxygen uptake

\section{Acknowledgements}

For the current manuscript, editorial assistance was provided by Dr. Claire Mulligan and Dr. Paul Overton (Beacon Medical Communications Ltd., Brighton, UK), funded by the University of Greifswald. The authors wish to thank all volunteers for their participation in the SHIP program. Moreover, we particularly thank all staff of the SHIP program and our numerous cooperation partners.

\section{Funding}

The SHIP study is part of a scientific collaboration at the Institute for Community Medicine of the University Hospital Greifswald (Funded by the Bundesministerium für Bildung und Forschung (BMBF; 01ZZ9603, 01ZZ0103, 01ZZ0403, 01ZZ0701) and the Ministry of Social Affairs, Integration and Equality of Mecklenburg-Vorpommern.

\section{Availability of data and materials}

The data that support the findings of this study are available from Prof. R. Ewert, but restrictions of the SHIP-study apply to the availability of these data, which were used under license for the current study, and so are not publicly available. Data are however available from the authors upon reasonable request and with permission of Prof. R. Ewert, Prof. H. Völzke or Prof. M. Dörr.

\section{Authors' contributions}

RE initiated the study, takes responsibility for the integrity of the data and the accuracy of the data analysis, SK and RE performed the AT determination, $\mathrm{AO}$ provided the statistical analysis and interpretation, SK, MD, $\mathrm{DH}, \mathrm{AO}, \mathrm{SG}, \mathrm{HV}$, and RE contributed substantially to the study design and interpreted the analysis, SK, MD, AO, and HV assessed the SHIP data, RE and $\mathrm{DH}$ wrote and $\mathrm{DH}$ coordinated the manuscript. All authors read and approved the final manuscript.

\section{Ethics approval and consent to participate}

The SHIP-study was approved by the ethics committee of Greifswald University (No. 043/13), and all volunteers gave their written, informed consent to participate in the SHIP-study. This consent included the anonymous processing of their data for statistical and scientific purposes. Our manuscript does not contain data that allow conclusions or tracking to an individual person.

\section{Competing interests}

The authors declare that they have no competing interests.

\section{Publisher's Note}

Springer Nature remains neutral with regard to jurisdictional claims in published maps and institutional affiliations.

\section{Author details}

${ }^{1}$ German Centre for Cardiovascular Research, Site Greifswald, Germany. ${ }^{2}$ DRK Kliniken Berlin Köpenick, Klinik für Kardiologie, S.-Allende-Str. 2-8, 12555 Berlin, Germany. ${ }^{3}$ Department of Internal Medicine B, University Hospital Greifswald, 17475 Greifswald, Germany. ${ }^{4}$ Institute for Community Medicine, University Hospital Greifswald, 17475 Greifswald, Germany. ${ }^{5}$ Department of Internal Medicine, Vivantes Klinikum Berlin-Spandau, 13585 Berlin, Germany.

Received: 15 January 2019 Accepted: 14 April 2019

Published online: 10 June 2019

\section{References}

1. Fletcher GF, Ades PA, Kligfield P, Arena R, Balady GJ, Bittner VA, et al. Exercise standards for testing and training: a scientific statement from the American Heart Association. Circulation. 2013;128(8):873-934.

2. Guazzi M, Adams V, Conraads V, Halle M, Mezzani A, Vanhees L, et al. EACPR/AHA scientific statement. Clinical recommendations for cardiopulmonary exercise testing data assessment in specific patient populations. Circulation. 2012;126(18):2261-74

3. Older P. Anaerobic threshold, is it a magic number to determine fitness for surgery? Perioper Med (Lond). 2013;2(1):2.

4. Junejo MA, Mason JM, Sheen AJ, Moore J, Foster P, Atkinson D, et al. Cardiopulmonary exercise testing for preoperative risk assessment before hepatic resection. Br J Surg. 2012;99(8):1097-104.

5. Arena R, Myers J, Guazzi M. The clinical significance of aerobic exercise testing and prescription: from apparently healthy to confirmed cardiovascular disease. Am J Lifestyle Med. 2008:2(6):519-36.

6. Palermo $P$, Corrà U. Exercise prescriptions for training and rehabilitation in patients with heart and lung disease. Ann Am Thorac Soc. 2017; 14(Supplement_1):S59-66.

7. Billinger SA, Arena R, Bernhardt J, Eng JJ, Franklin BA, Johnson CM, et al. Physical activity and exercise recommendations for stroke survivors: a statement for healthcare professionals from the American Heart Association/American Stroke Association. Stroke. 2014;45(8):2532-53.

8. Guazzi M, Arena R, Halle M, Piepoli MF, Myers J, Lavie CJ. 2016 focused update: clinical recommendations for cardiopulmonary exercise testing data assessment in specific patient populations. Circulation. 2016;133(24):e694-711.

9. Mezzani A, Hamm LF, Jones AM, McBride PE, Moholdt T, Stone JA, et al. Aerobic exercise intensity assessment and prescription in cardiac rehabilitation: a joint position statement of the European Association for Cardiovascular Prevention and Rehabilitation, the American Association of Cardiovascular and Pulmonary Rehabilitation, and the Canadian Association of Cardiac Rehabilitation. J Cardiopulm Rehabil Prev. 2012;32(6):327-50. 
10. Balady GJ, Arena R, Sietsema K, Myers J, Coke L, Fletcher GF, et al. Clinician's guide to cardiopulmonary exercise testing in adults: a scientific statement from the American Heart Association. Circulation. 2010;122(2):191-225.

11. Binder RK, Wonisch M, Corra U, Cohen-Solal A, Vanhees L, Saner H, et al. Methodological approach to the first and second lactate threshold in incremental cardiopulmonary exercise testing. Eur J Cardiovasc Prev Rehabil. 2008;15(6):726-34.

12. Mezzani A. Cardiopulmonary exercise testing: basics of methodology and measurements. Ann Am Thorac Soc. 2017;14(Supplement_1):S3-S11.

13. Westhoff $M$, Rühle KH, Greiwing A, Schomaker R, Eschenbacher $H$, Siepmann $\mathrm{M}$, et al. Positional paper of the German working group "cardiopulmonary exercise testing" to ventilatory and metabolic (lactate) thresholds. Dtsch Med Wochenschr. 2013;138(6):275-80.

14. DeCato TW, Bradley SM, Wilson EL, Hegewald MJ. Repeatability and meaningful change of CPET parameters in healthy subjects. Med Sci Sports Exerc. 2018;50(3):589-95.

15. Bensimhon DR, Leifer ES, Ellis SJ, Fleg JL, Keteyian SJ, Piña IL, et al. Reproducibility of peak oxygen uptake and other cardiopulmonary exercise testing parameters in patients with heart failure (from the heart failure and a controlled trial investigating outcomes of exercise traiNing). Am J Cardiol. 2008;102(6):712-7.

16. Myers J, Goldsmith RL, Keteyian SJ, Brawner CA, Brazil DA, Aldred H, et al. The ventilatory anaerobic threshold in heart failure: a multicenter evaluation of reliability. J Card Fail. 2010;16(1):76-83.

17. Garrard CS, Das R. Sources of error and variability in the determination of anaerobic threshold in healthy humans. Respiration. 1987;51 (2):137-45.

18. Behrens S, Andresen D, Bruggemann T, Ehlers C, Schröder R. Reproducibility of symptom-limited oxygen consumption and anaerobic threshold within the scope of spiroergometric studies in patients with heart failure. Z Kardiol. 1994:83(1):44-9.

19. Cohen-Solal A, Aupetit JF, Gueret P, Kolsky H, Zannad F. Can anaerobic threshold be used as an end-point for therapeutic trials in heart failure? Lessons from a multicentre randomized placebo-controlled trial. The VO2 French study group. Eur Heart J. 1994;15(2):236-41.

20. Pereira DA, Vieira DS, Samora GA, Lopes FL, Alencar MC, Lage SM, et al. Reproducibility of the determination of anaerobic threshold in patients with heart failure. Arq Bras Cardiol. 2010;94(6):771-8.

21. Ohuchi H, Nakajima T, Kawade M, Matsuda M, Kamiya T. Measurement and validity of the ventilatory threshold in patients with congenital heart disease. Pediatr Cardiol. 1996;17(1):7-14.

22. Hansen JE, Sun XG, Yasunobu Y, Garafano RP, Gates G, Barst RJ, et al. Reproducibility of cardiopulmonary exercise measurements in patients with pulmonary arterial hypertension. Chest. 2004;126(3):816-24.

23. Dubé BP, Mesbahi M, Beaucage F, Pepin V. Reliability of the determination of the Ventilatory threshold in patients with COPD. Med Sci Sports Exerc. 2016:48(2):210-8.

24. Sinclair RC, Danjoux GR, Goodridge V, Batterham AM. Determination of the anaerobic threshold in the pre-operative assessment clinic: inter-observer measurement error. Anaesthesia. 2009;64(11):1192-5.

25. Vainshelboim B, Rao S, Chan K, Lima RM, Ashley EA, Myers J. A comparison of methods for determining the ventilatory threshold: implications for surgical risk stratification. Can J Anaesth. 2017;64(6):634-42.

26. Völzke H, Alte D, Schmidt CO, Radke D, Lorbeer R, Friedrich N, et al. Cohort profile: the study of health in Pomerania. Int J Epidemiol. 2011;40(2):294307.

27. Ewert R, Ittermann T, Bollmann T, Spielhagen T, Dörr M, Schäper C, et al. Lung health data of the study of health in Pomerania - a review of samples, methods and first results. Pneumologie. 2017;71(1):17-35.

28. Gläser S, Ittermann T, Schäper C, Obst A, Dörr M, Spielhagen T, et al. The study of health in Pomerania (SHIP) reference values for cardiopulmonary exercise testing. Pneumologie. 2013;67(1):58-63.

29. Hennis PJ, Meale PM, Grocott MP. Cardiopulmonary exercise testing for the evaluation of perioperative risk in non-cardiopulmonary surgery. Postgrad Med J. 2011;87(1030):550-7.

30. Squires RW, Kaminsky LA, Porcari JP, Ruff JE, Savage PD, Williams MA. Progression of exercise training in early outpatient cardiac rehabilitation. J Cardiopulm Rehabil Prev. 2018;38(3):139-46.

31. Gaskill SE, Ruby BC, Walker AJ, Sanchez OA, Serfass RC, Leon AS. Validity and reliability of combining three methods to determine ventilatory threshold. Med Sci Sports Exerc. 2001;33(11):1841-8.

\section{Ready to submit your research? Choose BMC and benefit from:}

- fast, convenient online submission

- thorough peer review by experienced researchers in your field

- rapid publication on acceptance

- support for research data, including large and complex data types

- gold Open Access which fosters wider collaboration and increased citations

- maximum visibility for your research: over $100 \mathrm{M}$ website views per year

At BMC, research is always in progress.

Learn more biomedcentral.com/submissions 